\title{
Factors influencing calculation of capacity value of wind power: A case study of the Australian National Electricity Market (NEM)
}

\author{
Christy Nguyen, Chunbo Ma, Atakelty Hailu, Morteza Chalak \\ School of Agricultural and Resource Economics, University of Western Australia, Australia \\ Correspondent author: thithanhhue.nguyen@research.uwa.edu.au \\ Tel: +618 64884617 \\ M089, 35 Stirling Highway, Crawley WA 6009 Australia
}

\begin{abstract}
Calculation of wind power capacity values for risk assessment of power system adequacy has attracted great attention in the literature. And the most popular approach has been the Effective Load Carrying Capability (ELCC) method which allows for the consideration of key factors such as wind capacity factor, forced outage rates (F.O.R) of conventional power stations, system reliability targets, and the correlation between wind availability and system load. However, comparatively little attention has been paid to analysing the effects of other factors such as the number of wind farms and wind installed capacity, the length of historic time series data on demand and wind resources. This paper provides an in-depth analysis of how these factors influence the calculation of capacity value for the Australian National Electricity Market (NEM) power system using metered half-hourly wind and load data for 2006 to 2013. The analysis incorporates the periods with extreme risk events. Our results show that capacity values depend greatly on the design of the simulation model used, and highlight the importance of capturing wind and load data points relating to extremely high demand periods. We compare our NEM-wide estimates to recent estimates for the State of South Australia.
\end{abstract}

Index Terms: capacity value of wind power, power system operation and planning, Effective Load Carrying Capability (ELCC), wind power, Australian NEM power system

\section{Introduction}

Calculation of the capacity value of wind power for both interconnected and island grids has received a lot of attention in the past decade. The fundamental concept behind the need to calculate capacity value of wind power is that electricity demand could not be predicted with a high level of certainty when in fact electric power systems are required to have sufficient capacity (system adequacy) to meet customer demand instantaneously. As wind power penetration increases and gradually replaces conventional power generation, it is necessary to estimate its contribution to system adequacy. Wind's contribution to system adequacy expressed in equivalent-thermal capacity is its capacity value or capacity credit.

Determination of this capacity credit is challenging because of wind intermittency and the difficulty of forecasting long-term wind availability. Underestimation of wind power capacity value will cause an over-supply of costly capacity reserve while overestimation of firm-equivalent wind capacity could lead to power shortages. Besides, generation adequacy risk assessment is mainly based on the high demand periods; therefore, the primary focus of wind capacity value estimation is contributions during peak and extreme peak demand periods [1]. An approach that is widely used to quantify the contribution of wind generation to peak demand is the Effective Load Carrying Capability (ELCC) method [2] in which coincident historic time series for demand and available wind capacity are used directly in the risk calculation [3]. While this is a preferred method, it requires significant amount of historical wind and demand data which might not always be available. This becomes even more difficult when one attempts to assess wind contribution to extreme high demand periods because these events occur very rarely and records of these events could be inhomogeneous. In the case of the Australian NEM, for example, the extreme peak demand event has occurred only over a handful days during the 15 years since the NEM was established in 1999. We therefore analyse the effect of this extreme high demand event on wind capacity value in the NEM. Key factors that drive the capacity value results will also be analysed in this paper.

Capacity value depends on a number of factors that can be categorised in two groups. The first is the set of "inherent factors" that characterise wind generation and load features. These factors have 
been discussed widely [4-9] and include wind capacity factor, forced outage rate of conventional power stations (F.O.R), target system reliability level, and the general correlation between wind and load. The second group is a set of "subjective factors" and relates to the choice of calculation structure. These include the number of wind farms and wind installed capacity considered, the length of available historic time series that are used directly in the calculation, and the type of wind and load data inputs used in the simulation. The last factor refers to whether one uses the actual "historical sequencing" in which wind farms joined the grid or uses a "controlled interval" of time width providing a consistent wind capacity and load data for the simulation. The "historical sequencing" and "controlled interval" approaches are not well-defined in the literature; we describe the approaches with more detail in Section 2.4.1.

Although the "subjective factors" play a crucial role in the calculation of capacity value, they have received little attention in the literature. Addressing this research gap is a central theme of this study. It attempts to examine their effects on the estimation of wind power capacity values. In Australia, there are limited studies estimating capacity value of wind. Haslett and Diesendorf [10] used a numerical probabilistic model to investigate capacity value of wind power in Western Australia in 1978. This study provided an important analytical evaluation that considered correlation between wind and load. However, the study used data from Western Australia only. Moreover, the investigation was conducted more than 30 years ago and the data are not representative of recent or current wind power penetration levels. More recently, the Australian Energy Market Operator (AEMO) has published a report on wind contributions to peak demand in South Australia using historical wind and load data between 20082009 and 2013-2014 [11]. Like the first study, it focuses only on one State (with particularly high wind penetration) and may not be representative to the entire NEM.

In this paper, we focus on the Australian NEM power system as a case study covering all five eastern States, namely, New South Wales (NSW), Queensland (QLD), Victoria (VIC), South Australia (SA) and Tasmania (TAS). At present, the NEM system has more than 270 generators with system capacity of about 50GW, among which 31 are onshore wind generators with a total nameplate capacity of $3.1 \mathrm{GW}$.

The Institute of Electrical and Electronics Engineers (IEEE) Power and Energy Society Task Force on Capacity Value of Wind Generation [12] recommends that multiple years of data be used because wind power production varies from year to year, and calculations based on one or a few years might not be representative. [13] suggests that at least four to five years of data are necessary for reliable assessment of capacity value. On the other hand, findings by [3] show that even 25 years of data may not guarantee a robust estimation of wind capacity value because the frequency of extreme peak demand occurrences is very small. There is no simple rule of thumb to determine a reasonable length for the time series of wind and load data which should be used. The requirements depend on the power system under investigation as each system has its own unique wind and load patterns and also implications of the correlation between these patterns for meeting extreme peak demand periods. In this paper, we explore the effect of three "subjective factors": the length of the time window or data series considered; the type of modelling approach (historical sequencing or controlled interval); and the number of wind farms and wind installed capacity on the estimation of capacity value. We simulate eleven scenarios sequentially changing one factor in each scenario while holding the other two constant.

The paper is organised into five sections. Section 2 provides a graphical illustration of the method used in calculation of capacity value. The section also presents the eleven simulation scenarios developed to analyse the key factors influencing capacity value calculations. The features of the NEM power system, including its wind and load characteristics and data on extreme peak demands, are described in Section 3. The results of the capacity value calculation are presented and discussed in Section 4. The paper concludes in Section 5. 
The two most widely used capacity value metrics are Effective Load Carrying Capability (ELCC) and Equivalent Firm Capacity (EFC). ELCC is the additional load that the new wind generation can support without increasing the value of a chosen risk index. EFC is a measure of the size of the equivalent reliable capacity that would give the same risk level. Defining variables C, A, L as, respectively, total installed conventional generating capacity, available conventional capacity at a given time due to planned and unplanned forced outages, and demand (load) at a given time. The Loss of Load Probability (LOLP), denoted by $\mathrm{P}_{0}$, is the fraction of time (or probability) that available conventional capacity A falls below the load $\mathrm{L}$

$$
\mathrm{P}_{0}=\mathrm{P}_{\mathrm{r}}(\mathrm{A}<\mathrm{L})
$$

As a planning criterion, a typical value of $\mathrm{P}_{0}$ is in the range of $10^{-3}$ to $10^{-5}$ [6]. If a certain amount of hypothetical firm capacity $\mathrm{C}_{\mathrm{F}}$ is added to the grid, then LOLP is reduced to $\mathrm{P}_{\mathrm{F}}$, where

$$
\mathrm{P}_{\mathrm{F}}=\mathrm{P}_{\mathrm{r}}\left(\mathrm{A}+\mathrm{C}_{\mathrm{F}}<\mathrm{L}\right)
$$

Similarly, if wind available capacity at any time $\mathrm{W}$ (rated capacity $\mathrm{W}_{\mathrm{r}}$ ) is added to the grid, then LOLP becomes

$$
\mathrm{P}_{\mathrm{W}}=\mathrm{P}_{\mathrm{r}}(\mathrm{A}+\mathrm{W}<\mathrm{L})
$$

If capacity value is measured using ELCC, then

$$
\mathrm{P}_{0}=\mathrm{P}_{\mathrm{r}}(\mathrm{A}+\mathrm{W}<\mathrm{L}+\mathrm{ELCC})
$$

ELCC is the amount by which the load may be increased due to additional wind capacity while the original LOLP of $\mathrm{P}_{0}$ is maintained.

If capacity value is defined using the EFC criterion, then EFC is the value of $\mathrm{C}_{\mathrm{F}}$ obtained by equating $\mathrm{P}_{\mathrm{F}}$ and $\mathrm{P}_{\mathrm{W}}$ from equation (2) and (3). $\mathrm{C}_{\mathrm{F}}$ equals a coefficient $\alpha$ multiplied by available wind capacity $\mathrm{W}$, where $\alpha$ is usually greater than 1.0 .

$$
\mathrm{C}_{\mathrm{F}}=\alpha \mathrm{W}
$$

The capacity value metric should be chosen to facilitate the objective of a particular calculation; however, ELCC and EFC are closely related mathematically, and results and techniques applicable to one may easily be transferred to the other [14].

\subsection{Preferred ELCC-based Calculation Method}

We chose the ELCC-based method to calculate capacity value of wind power because it is the method recommended by the IEEE Power and Energy Society Task Force on Capacity Value of Wind Generation [12]. ELCC is measured using Loss of Load Expectation (LOLE) that is the expected number of hours or days, during which the load will not be met. LOLE can be calculated through direct use of historic demand and wind time series. This method automatically incorporates the available statistical information on the relationship between wind availability and demand and it is the most relevant method for assessing system risk as it relates supply to demand during the hours of very high peak demand $[12,15]$.

The risk index used in LOLE is defined as

$$
[\mathrm{LOLE}]=\sum_{t}[L O L P]_{t}
$$

where the Loss of Load Probability for period $t\left(\operatorname{LOLP}_{\mathrm{t}}\right)$ is defined as the probability that the available generation in period $t$ is less than demand. The periods considered may be half-hours, hours or days. 
The results of LOLE calculations based on different period lengths are not directly comparable; for example hourly LOLE would count a consecutive 3 hour shortage as 3 hours, whereas daily LOLE would effectively count it as one day. Detailed application of this method is discussed in section 2.3 and 2.4.

\subsection{Graphical Illustration of ELCC-based Method}

161

162

163

164

165

166

167

168

169

170

171

172

Descriptions of the method have been provided mainly using computer algorithms ([13, 16]), mathematical models [14, 17] or plain text descriptions [8, 12]. Below, we provide graphical illustrations using real wind and load data recorded on 30-minute intervals in the NEM.

The three graphs below (Fig.1-3) represent three sequencing steps in obtaining ELCC value. In the first graph, two curves and one straight line have been plotted in chronological order of a defined time period (e.g. hours per year or multiple years). "Available capacity" is the predetermined target system reliability of $95 \%-99 \%{ }^{1}$ applied in the NEM over the long-term and is represented by the straight line. The load and wind power production curves represent fluctuation of electricity demand against available wind generation over time. The hours of excess load, over and above available capacity, is the LOLE $_{1}$ which is the number of hours that load is unserved due to capacity deficit. In this example, $\mathrm{LOLE}_{1}$ equals the 12 hours marked by the oval.

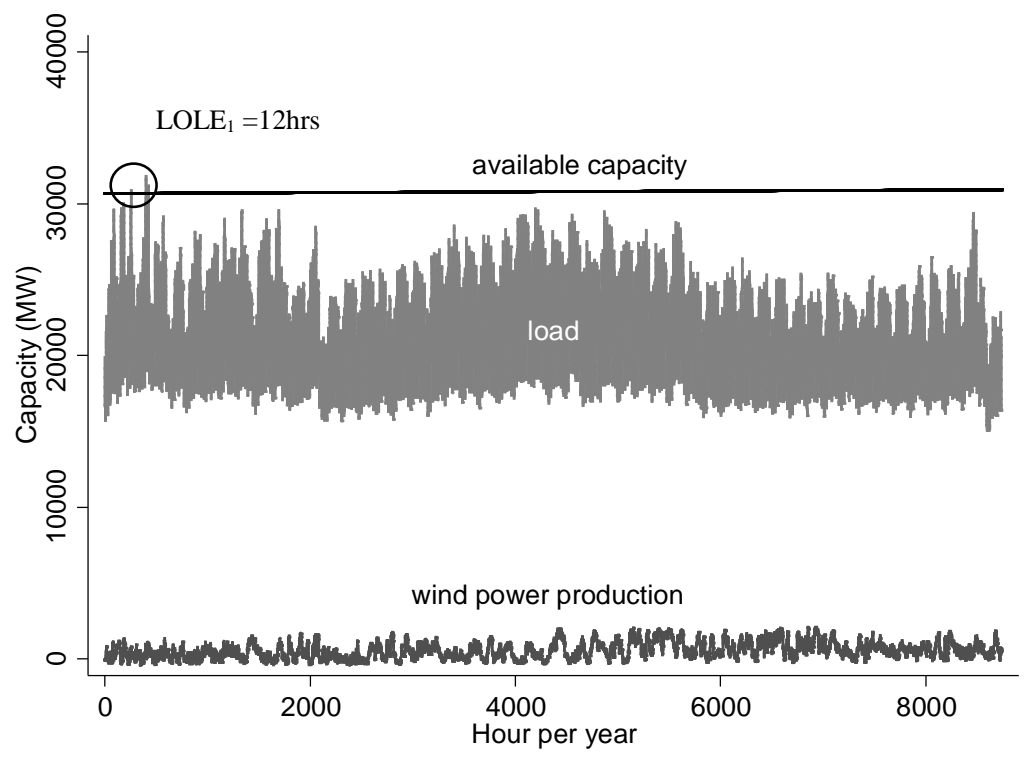

Fig.1: Capacity deficit without wind power (LOLE=12hrs)

1 Reliability of a power system refers to the probability of its satisfactory operation over the long run. It denotes the ability to supply adequate electric service on a nearly continuous basis, with few interruptions over an extended time period [18]. This paper, targets 95-99 per cent of the hours served for the power system functioning adequately 


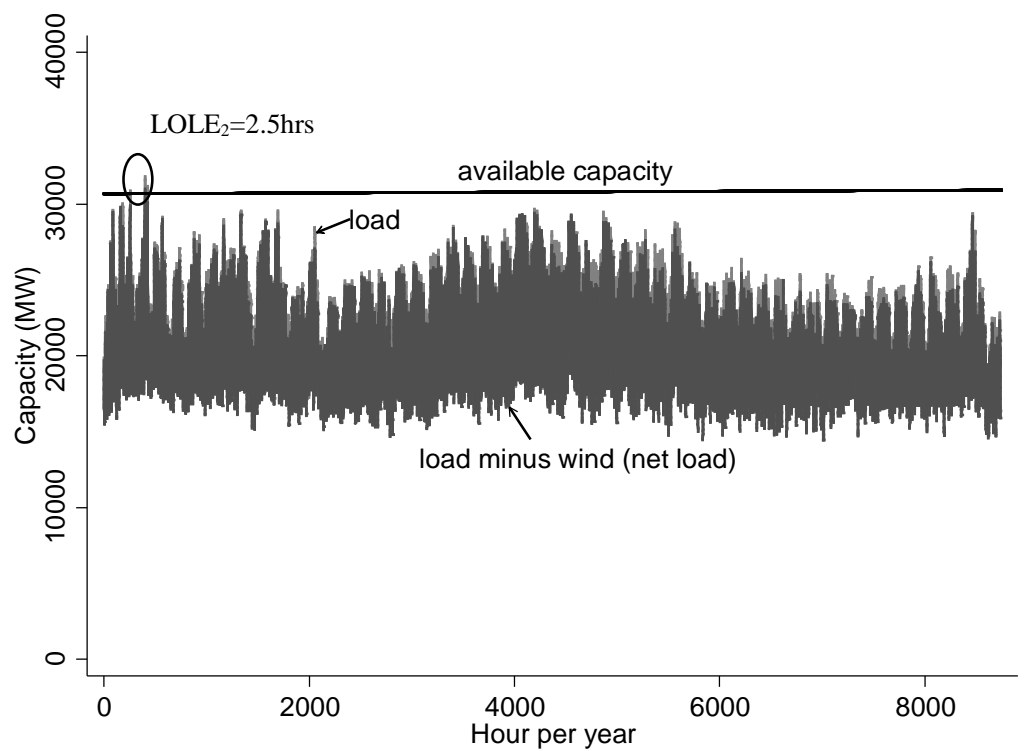

Fig.2: Capacity deficit with wind power (LOLE=2.5hrs)

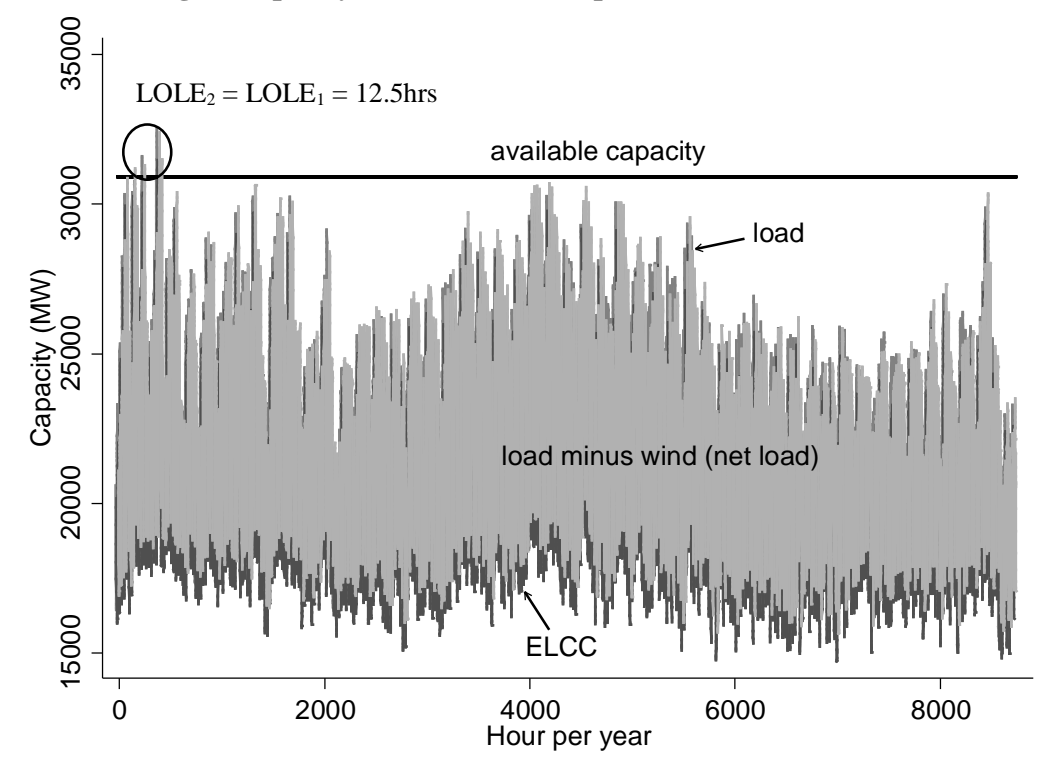

Fig.3: Capacity value of wind power is ELCC that returns LOLE to $12 \mathrm{hrs}$

In the second graph, wind output is treated as negative load, and then it is removed from the load time series resulting in the net load curve (load minus wind power) that is depicted in Fig. 2. In the same manner as Fig. 1, the $\mathrm{LOLE}_{2}$ is calculated as the total number of hours where load is unserved (Fig. 2). $\mathrm{LOLE}_{2}$ is now lower (equals to 2.5 hours in our example) than the target $\mathrm{LOLE}_{1}$ in step 1. Finally, the third graph presents a required increase in the amount of load over time series that makes $\mathrm{LOLE}_{2}$ equal to target LOLE ${ }_{1}$. This amount of load increase to maintain target reliability level is called the ELCC. It is alternatively known as capacity value or capacity credit of wind (Fig. 3). Capacity value of wind can be presented in absolute terms (MW) or as a percentage of installed wind capacity.

In the case of the NEM power system, half-hourly metered wind and load data in the period of 20062013 is available, and hence we use directly in the calculation representing the geographical dispersion of the historic wind fleet for the years being studied. To provide a meaningful comparison of capacity value results, we scale ELCC value according to the wind capacity installed for the years considered in the analysis.

\subsection{Simulation Scenarios}

\subsubsection{Historical sequencing (HS) and controlled interval (CI) simulation data}


A few studies have conducted capacity value assessments but do not clearly explain how wind and load data series were constructed in their models $[5,8,18-20]$. Therefore, in this section, we first describe the two types of modelling approaches with regard to the wind and load time series data used. We then apply both approaches in our simulations for capacity value estimation.

202

203

204

205

206

207

208

209

210

211

212

213

214

215

First, we separate two types of modelling approaches: historical sequencing (HS) and controlled interval (CI). The HS approach covers wind and load time series data reflecting the actual historical sequence in which the wind farms joined the grid. That is, the modelling relies on the complete historical load data without truncation. This, however, means that the number of wind farms operating at different points in time will be different and it typically requires long-period of data (e.g. over 5-10 years). This issue is addressed in the CI approach, which controls the width and location of the time window explored so that the number of wind farms is constant within that time window or interval. Multiple years of historical wind and load data are ideal for calculating capacity value in the ELCC method; however, they are not always available in every power system. Therefore, we examine whether the CI approach covering a relatively short period with controlled capacity can still provide a meaningful capacity value for systems that have limited wind and load data availability.

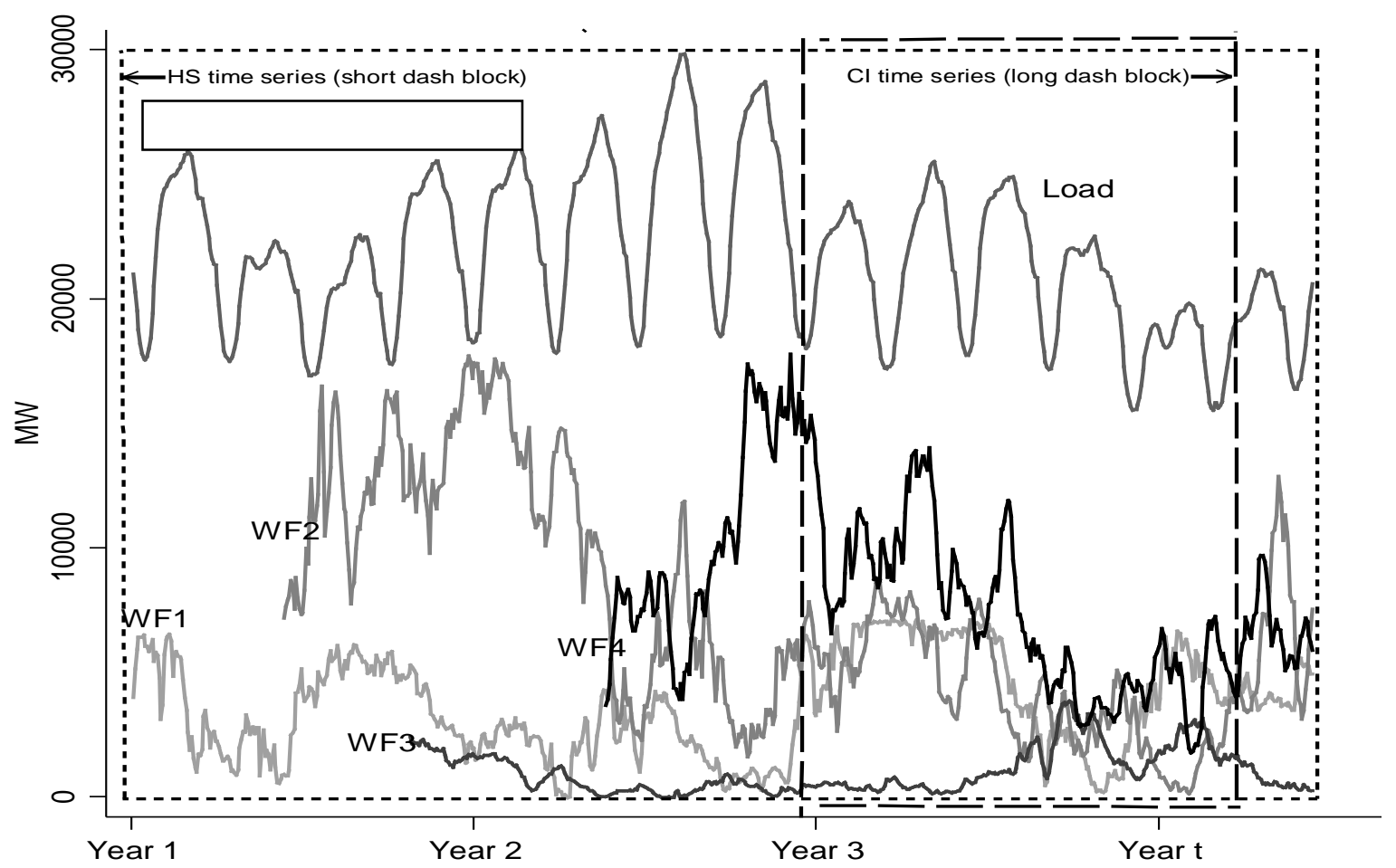

Figure 4: Illustration of "historical sequencing" and "controlled interval” of wind and load time series data

Fig.4. provides examples of the two types of modelling approaches with illustrative wind and load data series associated with each approach. Suppose we have wind and load data of a power system from year 1 to year t, in which four wind farms (WF1-WF4) joined the grid at different points in time. Suppose at the beginning of year 1, wind farm 1 (WF1) joined the grid; suppose further that wind farms 2 and 3 (WF2, WF3) joined the grid in late in the first year and that wind farm 4 (WF4) joined the grid in the middle of the second year. To construct a historical wind and load data series, we can either consider long-term correlation of wind and load from year 1 to year $t$ (short-dash block that we called "historical sequencing"), or we could take the controlled interval approach and focus only on a shorter controlled time interval or even a single year (long-dash block). Each approach has its pros and cons. HS type of data is useful if the aim is to investigate the long-term correlation of wind and load. HS is also likely to produce more reliable capacity value estimates because it utilises a longer data series. However, using HS type data requires scaling wind data and interpreting the results carefully because the number of wind farms varies through the period and is smaller at the start of the period than at the end when the power system is likely to be more developed and mature at the end. 
The CI type of data, on the other hand, can be applied where long-term historical wind and load data is not available. The CI type of data is also useful when assessing the immediate physical impact of new wind farms joining the grid on a power system. In the example provided above, one could construct CI data for the two years (1-2) in which WF 2 \& 3 joined the grid (see Fig.4). In our simulation model, we construct different CI time intervals to capture the different stages of the NEM system. For example, one of the years (2009) is selected because it is the year where the highest load occurred. Another year (2013) was selected because all 31 wind farms were fully operating by then. A window 3-4 years long (2009-2013) was used because it represents the latest development stage of the NEM power system.

The choice of either HS or CI time series data plays an important role in shaping the capacity value of wind power. HS type of data is applicable if past conditions affect present conditions. The CI type of data, on the other hand, assumes historical conditions have insignificant or zero effect on present conditions. Fig. 5 provides actual historical schedule for the 31 wind farms that joined the NEM grid since December 2005 and examples of two HS and two CI scenarios used in our calculation.

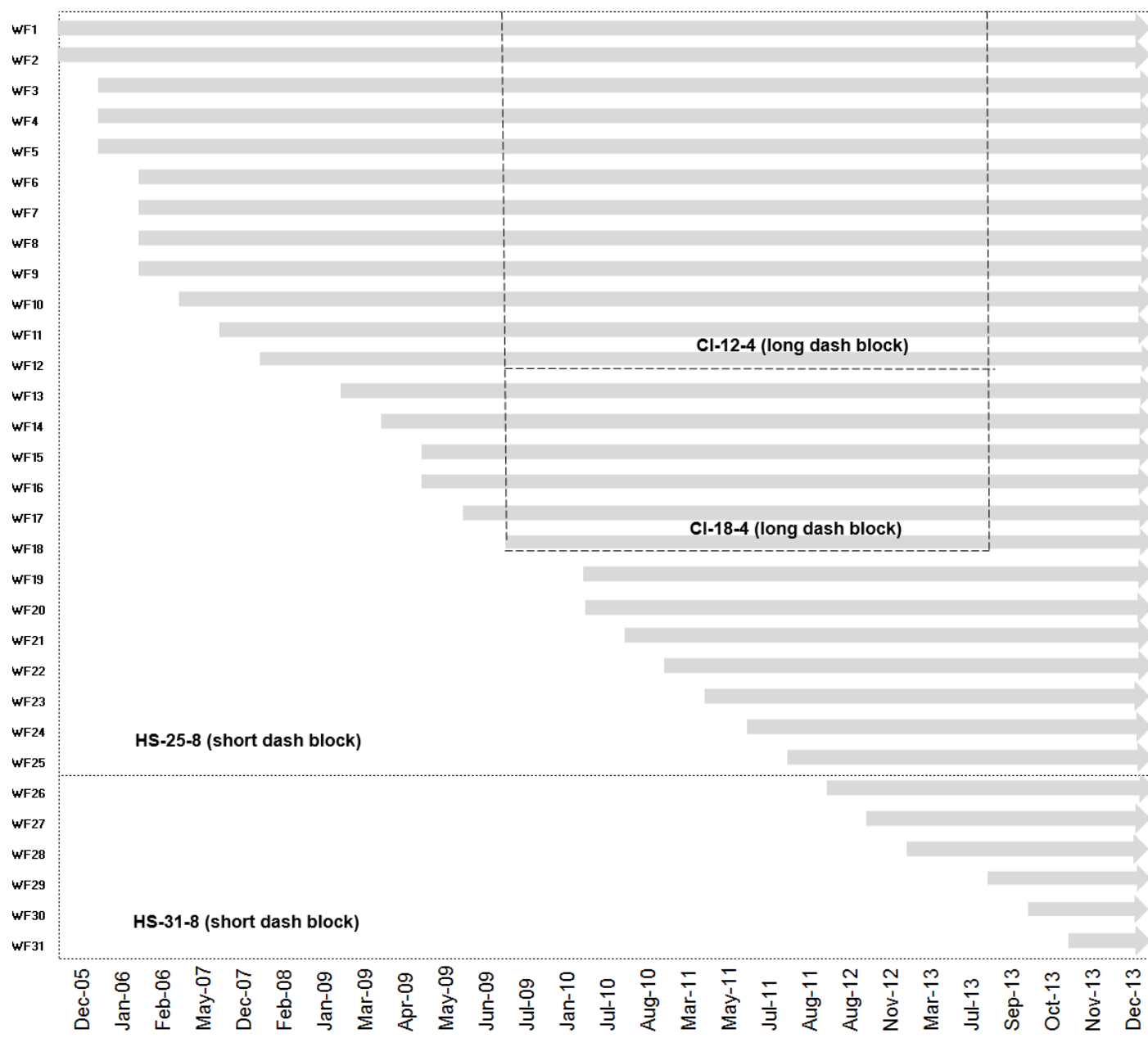

Fig.5: Examples of HS and CI Scenarios

\subsubsection{Simulation Scenarios}

We develop the eleven different simulation scenarios to examine the effect of the following three key subjective factors on the capacity value of wind power:

a) the modelling approach: HS or CI;

b) the number of wind farms and installed wind capacity considered in the simulation model; and

c) the length of historical time series (e.g. multiple years or a single year) included in the simulation model. 
Eleven simulation scenarios are analysed using similar reliability standards (between 95\% to 99\%). The first six simulation models are HS-based models while the last five models are CI-based simulation. Each wind generator connects to the NEM network at different stages, but the earliest wind power generation data obtained from the AEMO is in mid-December 2005, therefore our time array in simulation models starts in January 2006 till December 2013. The longest HS data arrays span from January 2006 to December 2013 covering 8 years while the longest CI data arrays cover only four and half years (from July 2009 to December 2013). The shortest data array for both HS and CI is one year (2009 or 2013). The nine scenarios refer to different period lengths and number of joining wind farms, with two of the periods covering only single years (2009 and 2013). The reason we single out these two is because of record of extreme peak demand events that occurred in January 2009 and because 2013 is the most recent year that covers the full operation of 31 wind farms. Table 1 provides details of the eleven simulations considered, each simulation is characterised by its ID (for example: HS-18-1 means simulation covers historical sequencing type of data for 18 wind farms in one year).

Table 1

Eleven Simulation Scenarios Considered

\begin{tabular}{c|l|c|c|c|c|c}
\hline $\begin{array}{c}\text { Simulation } \\
\text { No }\end{array}$ & $\begin{array}{c}\text { Simulation } \\
\text { ID }\end{array}$ & Approach & No. of years & Period & $\begin{array}{c}\text { No. of } \\
\text { wind } \\
\text { farms }\end{array}$ & $\begin{array}{c}\text { Wind installed } \\
\text { capacity (MW) }\end{array}$ \\
\hline 1 & HS-18-1 & HS & 1 & Jan 09-Dec 09 & 18 & 1,617 \\
2 & HS-18-3 & HS & 3 & Jan 09-Dec 11 & 18 & 1,617 \\
3 & HS-25-3 & HS & 3 & Jan 09-Dec 11 & 25 & 2,114 \\
4 & HS-25-8 & HS & 8 & Jan 06-Dec 13 & 25 & 2,114 \\
5 & HS-31-8 & HS & 8 & Jan 06-Dec 13 & 31 & 3,145 \\
6 & HS-31-4 & HS & 4 & Jan 10-Dec 13 & 31 & 3,145 \\
7 & CI-12-1 & CI & 1 & Jan 09-Dec 09 & 12 & 963 \\
8 & CI-12-4 & CI & 4 & Jul 09-Jul 13 & 12 & 963 \\
9 & CI-18-4 & CI & 4 & Jul 09-Jul 13 & 18 & 1,617 \\
10 & CI-18-3 & CI & 3 & Aug 10-Aug 13 & 18 & 1,617 \\
11 & CI-21-3 & CI & 3 & Aug 10-Aug 13 & 21 & 1,899 \\
\hline
\end{tabular}

In Table 1, the first six simulations used Historical Sequencing (HS) approach and last five simulations all used the Controlled Interval (CI) approach.

Capacity value estimates can be compared between adjacent scenarios according to the sequencing shown in Table 1 . Only one subjective factor is varied between adjacent rows. Thus, we first compare results from simulation 1 (HS-18-1) and simulation 2 (HS-18-3) which differ only in the number of years covered but have the same simulation approach (HS) and include the same number of wind farms (18). This comparison evaluates the effect of variation in the time window. The next pair compared, simulation 2 (HS-18-3) and simulation 3 (HS-25-3), differ only in the number of wind farms (18 versus 25) as do simulations 4 and 5 . The comparison between simulations 3 and 4, and between 5 and 6 , focuses on the effect of the time interval. The story with the CI approach is similar, adjacent simulations vary in only one subjective factor.

Eleven simulations contain various time length and wind installed capacity due to simulation design; therefore, to make the results comparable, we standardize the results by consistently scale-up wind capacity values as percentages of wind installed capacity at 20 percent wind penetration level ${ }^{2}$ while keeping all other parameters unchanged. Results of capacity value from eleven scenarios are then compared at this penetration level. The chosen 20 percent wind penetration level is based on the nation-

${ }^{2}$ There are two metrics are usually used to define wind capacity penetration: capacity or energy penetration. Capacity penetration is a ratio of installed wind capacity and total installed capacity. Energy penetration is a ratio of annual wind energy and annual total energy demand. In this paper, we followed the literature $[5,22]$ to define capacity penetration as a ratio of installed wind capacity and peak load. The reason we apply this metric is because we aim to remove the component of reserve capacity in the total installed capacity. For those power systems that have high reserve capacity margin like NEM (33\% of total installed capacity in 2013), it is necessary to remove this component to accurately reflect the real wind capacity penetration. 
wide Large-scale Renewable Energy Target (LRET) scheme, aiming at least 20 percent of electricity being produced from renewables by $2020[21]$.

\section{The Australian NEM Power System}

\subsection{Wind Installed Capacity and Grid Connection Schedule}

Australia in common with many other countries is facing a potential dramatic increase in wind energy production. At the end of 2013, there were more than 1,000 wind turbines spread across 31 operating wind farms in the NEM with total scheduled and semi-scheduled generating capacity of about 3.1GW[22]. In term of wind energy production, nearly 8,000 GWh of electricity has been produced, accounting for 4.1 percent of the NEM's overall electricity generation in 2013. The 31 wind farms considered in our study are located in four States including NSW, VIC, SA and TAS. Queensland has had one small wind farm with installed capacity of 12MW since 2000; but we don't include that farm in our analysis because it is not recorded in the NEM central dispatch system.

Table 2 presents the wind generators that have joined the NEM since 2006, including their IDs, locations, nameplate capacities and commencement dates. SA had the highest number of wind generators (thirteen generators with installed capacity of 1,300MW), followed by VIC (eight generators with 1,077MW), NSW (five generators with 431MW) and TAS (two generators with 308MW).

Table 2

Wind Generators in the Australian NEM

\begin{tabular}{r|l|l|r|r|r|l|l|r|r}
\hline No & $\begin{array}{l}\text { Wind } \\
\text { generator ID }\end{array}$ & Region & $\begin{array}{c}\text { Capacity } \\
\text { (MW) }\end{array}$ & $\begin{array}{c}\text { Commission } \\
\text { date }\end{array}$ & No & $\begin{array}{c}\text { Wind } \\
\text { generator ID }\end{array}$ & Region & $\begin{array}{c}\text { Capacity } \\
\text { (MW) }\end{array}$ & $\begin{array}{c}\text { Commission } \\
\text { date }\end{array}$ \\
\hline 1 & WOOLNTH1 & TAS & 140 & Dec-05 & 16 & CULLRGWF & NSW & 30 & May-09 \\
2 & LKBONNY1 & SA & 80.5 & Dec-05 & 17 & CAPTL_WF & NSW & 140 & Jun-09 \\
3 & WPWF & SA & 90.75 & Jan-06 & 18 & PORTWF & VIC & 164 & Jul-09 \\
4 & CATHROCK & SA & 66 & Jan-06 & 19 & LKBONNY3 & SA & 39 & Jul-10 \\
5 & MTMILLAR & SA & 70 & Jan-06 & 20 & NBHWF1 & SA & 132.3 & Jul-10 \\
6 & CHALLHWF & VIC & 53 & Feb-06 & 21 & WATERLWF & SA & 111 & Aug-10 \\
7 & YAMBUKWF & VIC & 30 & Feb-06 & 22 & GUNNING1 & NSW & 47 & Mar-11 \\
8 & CNUNDAWF & SA & 46 & Feb-06 & 23 & WOODLWN1 & NSW & 48 & May-11 \\
9 & STARHLWF & SA & 34.5 & Feb-06 & 24 & BLUFF1 & SA & 52.5 & Jul-11 \\
10 & LKBONNY2 & SA & 159 & May-07 & 25 & OAKLAND1 & VIC & 67 & Aug-11 \\
11 & HALLWF1 & SA & 94.5 & Dec-07 & 26 & MACARTH1 & VIC & 420 & Aug-12 \\
12 & SNOWTWN1 & SA & 99 & Feb-08 & 27 & MLWF1 & VIC & 20 & Nov-12 \\
13 & WAUBRAWF & VIC & 192 & Mar-09 & 28 & MUSSELR1 & TAS & 168 & Mar-13 \\
14 & CLEMGPWF & SA & 57 & Apr-09 & 29 & SNOWSTH1 & SA & 126 & Sep-13 \\
15 & HALLWF2 & SA & 71.4 & May-09 & 30 & MERCER01 & VIC & 131 & Oct-13 \\
& & & & & & & & &
\end{tabular}

\subsection{Wind and Load Characteristics}

Half-hourly wind and load data series covering 31 wind generators were available across the years from 2006 to 2013. Fig. 6 shows the normalised diurnal mean wind and load over the past eight years in the NEM. Insignificant correlation between wind availability and electricity demand in the NEM is recognised in this graph. Peak daily electricity demand is from 6:00 to 9:00 pm whereas highest wind production occurs between 10:00 pm and 2:00 am. This characteristic feature of the NEM is important in the determination of the capacity value for wind power. 


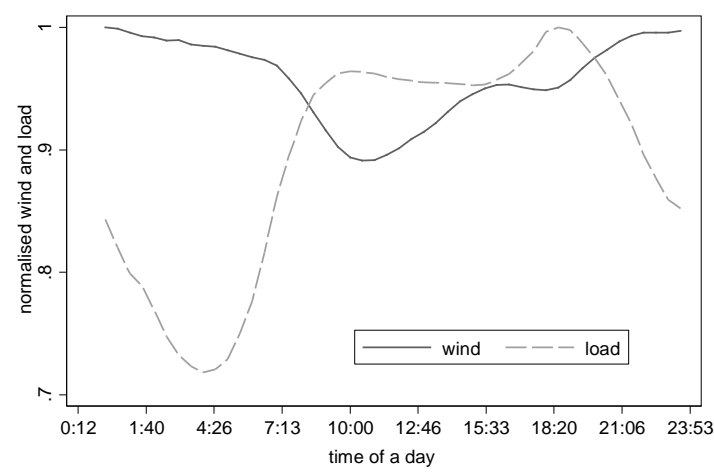

Fig.6: Normalised mean wind and load in 2006-2013 using real half-hourly time resolution

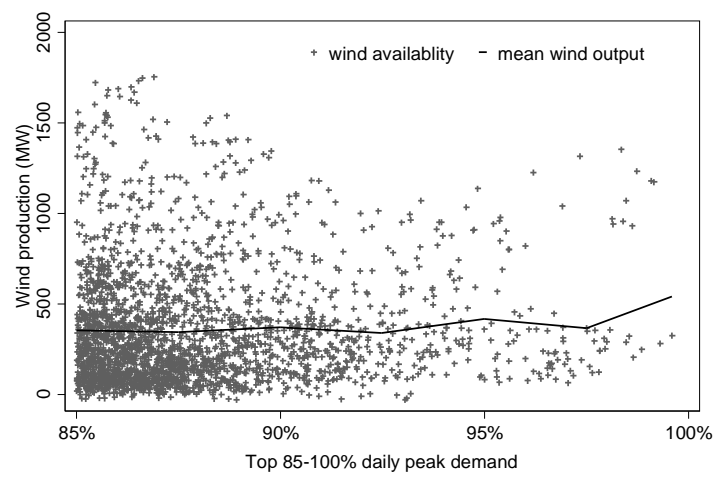

Fig.7: Wind contribution to 85 to100 percentile of peak demand in 2006-2013

Fig.7 plots the wind power generation against the top 85-100 percentile of peak load in the years of 2006-2013 to show how statistically wind availability contributes to peak demand. In the top 85 percentile of peak demand, wind generation contributes mostly from zero to less than 1,000 MW, accounting for about $30 \%$ of full capacity. In the top $95-100 \%$ of peak demand, wind power production contributes from zero to $500 \mathrm{MW}$ (or 16\% of installed capacity). Mean wind output contribution to peak demand varies from 300 to 600 MW, representing $10-17 \%$ of full load capacity.

\subsection{Data of Extreme Peak Demands}

In assessing the robustness of a calculation's results, it is necessary to consider the volume of statistical information on the wind availability at times of high demand because contribution of wind during these periods determines the generation adequacy risk assessment. It is more difficult to assess power system adequacy under extreme conditions as extreme high demand occurs infrequently. For this purpose, an extreme peak demand is defined as one exceeding $99 \%$ of average peak demand and the average peak demand value is determined by averaging peak demand in summer and winter under normal weather condition. Average peak demand value in this case is driven by economic and demographic factors (e.g. population growth, GDP growth, technology use, etc.). The focus on average peak demand helps us to remove the effect of "ad hoc" weather fluctuations on peak demand. In the case of NEM, the average peak demand of 33,800 MW observed in the 2006-2013 period is used as a benchmark. Table 3 summarises the data on extreme demands exceeding 33,800 MW in the past 15 years of operation [23]. There were only 9 days where the $99 \%$ average peak threshold was exceeded. Moreover, these days occurred in five distinct periods and in two particular months, January and February (2009 and 2011).

Table 3

Periods with Demands Above 99\% of Average Peak in Period of 2006-2013

\begin{tabular}{l|c|c}
\hline \multicolumn{1}{c|}{ Period } & No of days & No of hours \\
\hline 28-30 Jan 2009 & 3 & 20.5 \\
5-6 Feb 2009 & 2 & 6.5 \\
11 Jan 2011 & 1 & 0.5 \\
31 Jan 2011 & 1 & 6.5 \\
1-2 Feb 2011 & 2 & 11 \\
\hline
\end{tabular}

The high demand event for January 2009 was due to extreme hot weather leading to the increased utilisation of cooling loads while the supply problem was exacerbated by capacity reductions of both generators and transmission elements. Generation and transmission elements also experience higher 
than 800 MW of load was shed in Victoria and South Australia because of supply shortfall [24].Similarly in 2011, high temperature (above 40C degree) across the middle of Australia drove unusual high demand especially in South Australia and New South Wales, coincident with a reduction in output in a power station in Victoria, leading to the second highest demand in the NEM-wide history only after the heatwave of January 2009.

These extreme weather conditions and unusually high demand events are low probability events; but they can still reoccur in the future and need to be considered in the analysis. Moreover, as can be seen in the next section, extreme weather conditions and peak demands have significant influence on the capacity value of wind power.

\section{Results}

\subsection{Capacity Value of Wind Power}

Table 4 presents the results from the capacity value calculation in absolute terms (MW) for all the eleven simulation scenarios at 20 percent wind penetration; the results are presented in percentage terms in Fig.8 (a-g). Wind penetration level is measured as a ratio between nameplate wind capacity and peak demand $[5,18]$. The capacity values in all scenarios are measured at $95 \%$ to $99 \%$ system reliability target.

Table 4

Results of Capacity Value of Wind Power at 95\% to 99\% System Reliability Scaled Up at $20 \%$ Wind Penetration Level

\begin{tabular}{|c|c|c|c|c|c|c|c|c|c|}
\hline $\begin{array}{c}\text { Sim. } \\
\text { No. }\end{array}$ & Sim. ID & Approach & $\begin{array}{c}\text { No. of } \\
\text { years }\end{array}$ & Period & $\begin{array}{c}\text { No. of } \\
\text { wind } \\
\text { farms }\end{array}$ & $\begin{array}{c}\text { Wind } \\
\text { installed } \\
\text { capacity } \\
\text { (MW) }\end{array}$ & $\begin{array}{c}\text { Capacity } \\
\text { value } \\
\text { (MW) }\end{array}$ & $\begin{array}{c}\text { Capacity } \\
\text { value } \\
\text { \% of wind } \\
\text { penetration) }\end{array}$ & $\begin{array}{c}\text { Mean } \\
\text { wind } \\
\text { capacity } \\
\text { factor } \\
(\%)\end{array}$ \\
\hline 1 & HS-18-1 & HS & 1 & Jan 09-Dec 09 & 18 & 1,617 & $260-296$ & $7.4-7.9$ & 30.9 \\
\hline 2 & HS-18-3 & HS & 3 & Jan 09-Dec 11 & 18 & 1,617 & $260-296$ & $7.4-7.9$ & 31.2 \\
\hline 3 & HS-25-3 & HS & 3 & Jan 09-Dec 11 & 25 & 2,114 & $260-296$ & $7.4-7.9$ & 31.3 \\
\hline 4 & HS-25-8 & HS & 8 & Jan 06-Dec 13 & 25 & 2,114 & $260-296$ & $7.4-7.9$ & 30.9 \\
\hline 5 & HS-31-8 & HS & 8 & Jan 06-Dec 13 & 31 & 3,145 & $260-296$ & $7.4-7.9$ & 30.6 \\
\hline 6 & HS-31-4 & HS & 4 & Jan 10-Dec 13 & 31 & 3,145 & $418-474$ & $7.5-8.2$ & 32.5 \\
\hline 7 & CI-12-1 & CI & 1 & Jan 09-Dec 09 & 12 & 963 & $260-296$ & $7.4-7.9$ & 30.8 \\
\hline 8 & CI-12-4 & CI & 4 & Jul 09-Jul 13 & 12 & 963 & $310-338$ & $16.7-17.3$ & 31.3 \\
\hline 9 & CI-18-4 & CI & 4 & Jul 09-Jul 13 & 18 & 1,617 & $348-418$ & $18.2-20.9$ & 32.7 \\
\hline 10 & CI-18-3 & CI & 3 & Aug 10-Aug 13 & 18 & 1,617 & $390-430$ & $18.9-21.5$ & 32.5 \\
\hline 11 & CI-21-3 & CI & 3 & Aug 10-Aug 13 & 21 & 1,899 & $425-501$ & $19.0-23.6$ & 33.5 \\
\hline
\end{tabular}

In general, capacity values vary, depending on the design of simulation models. These value are affected by three factors considered, namely, type of wind and load time series data (HS or CI), number of wind farms and installed capacity, and number of years considered in the simulation models. In absolute terms, capacity values vary from 260MW to 501MW. That means out of the 3,145MW of wind installed, wind power generation contributes to peak demand between $260 \mathrm{MW}$ and $501 \mathrm{MW}$, representing the amount of firm capacity or equivalent thermal capacity could be displaced by wind power. Mean capacity factors lie in the range of $30 \%$ to $34 \%$, i.e. overall, wind output accounts for $30 \%$ to $34 \%$ of its potential output at its nameplate capacity.

In percentage terms, capacity value of wind power is found to be sensitive to the penetration level (Fig.8a-e). At extremely low wind penetration levels (below 2\%), capacity value is in the $30 \%$ to $34 \%$ range equal to wind capacity factor. This capacity value deceases rapidly and levels off at greater penetration level. Our results are consistent with those in Haslett and Diesendorf [10].

We, however, denoted in Fig.8a that capacity values in simulations 1 to 5 and 7 (HS-18-1, HS-18-3, HS-25-3, HS-25-8, HS-31-8 and CI-12-1) are similar and fall in the narrow range of 260MW-296MW, irrespective of the length of the time window (1, 3 or 8 years) and number of wind farms $(12,18,21,25$ 
or 31). Five of these simulations are based on the HS method (simulation 1 to 5), and one is based on the CI method (simulation 7). Capacity value varies from $7 \%$ to $9 \%$ wind installed capacity as wind penetration level increases up to $20 \%$.

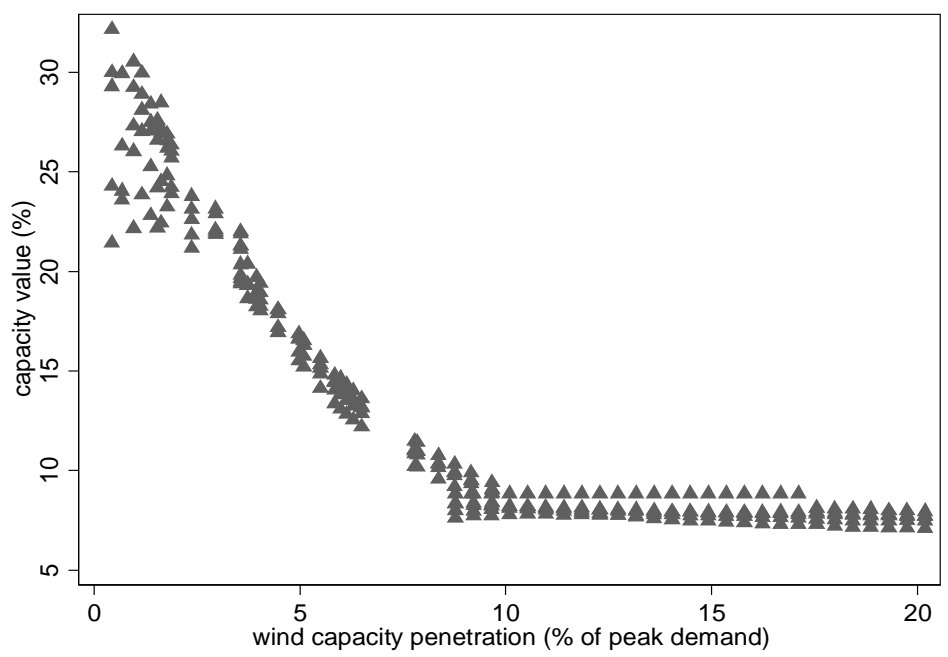

In contrast, capacity values cover a wide range in all the remaining simulations $(6,8,9,10$, and 11$)$ as shown in Fig.8b-f ranging from 310MW to 501MW equivalent or between $17 \%$ to $24 \%$ of wind penetration levels. The contrast reveals that there are periods in these simulations where wind generates little or no output during peak demand periods that are responsible for the low capacity value estimates obtained (Fig.8a). Higher wind output contributions during peak demand periods will generate higher wind capacity values (Fig.8b-f).

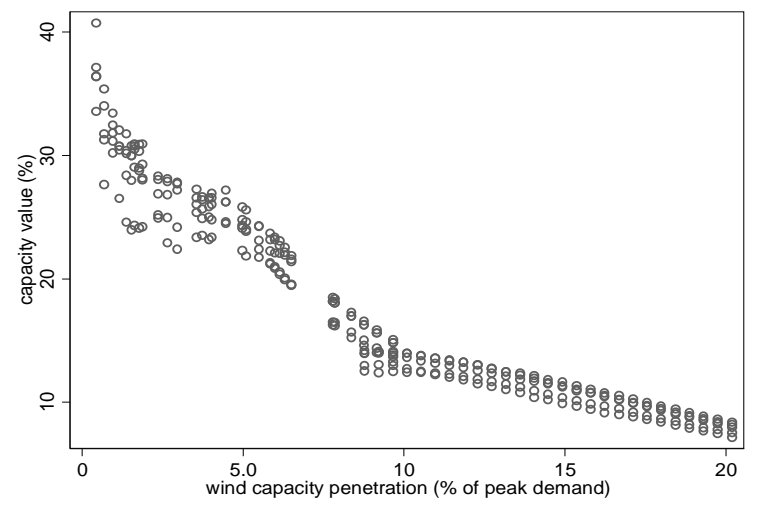

Fig 8(b): Wind capacity value in simulation 6 (HS-31-4)

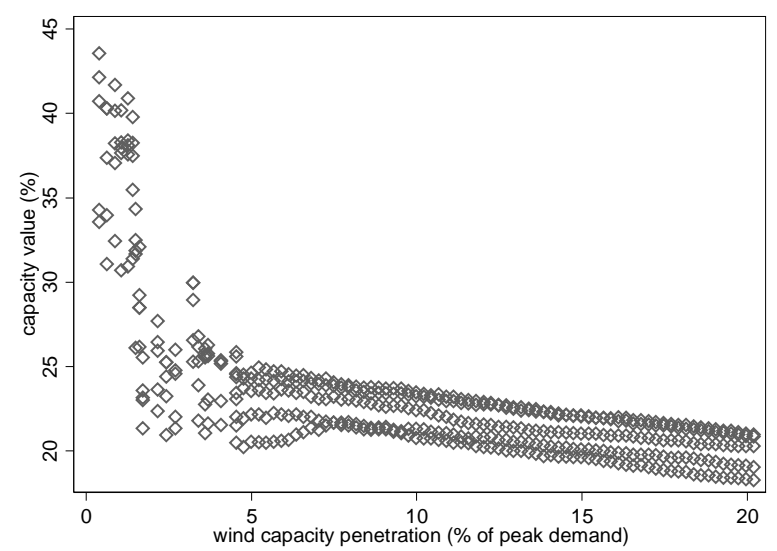

Fig 8(d): Wind capacity value in simulation 9 (CI-18-4)

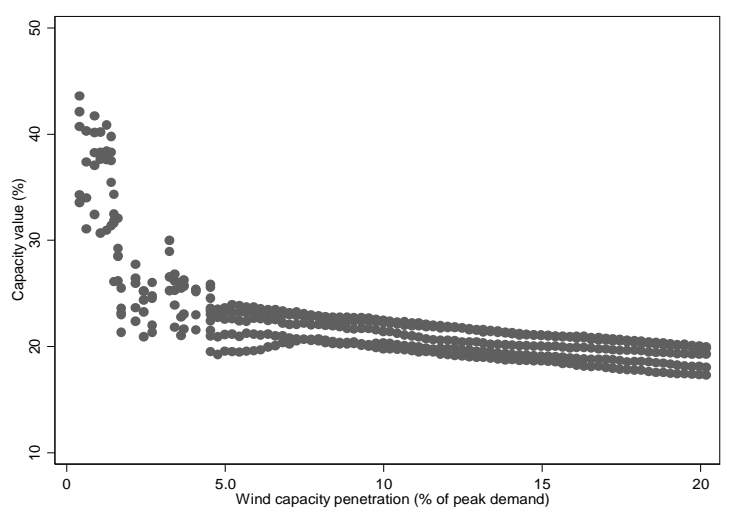

Fig 8(c): Wind capacity value in simulation 8 (CI-12-4)

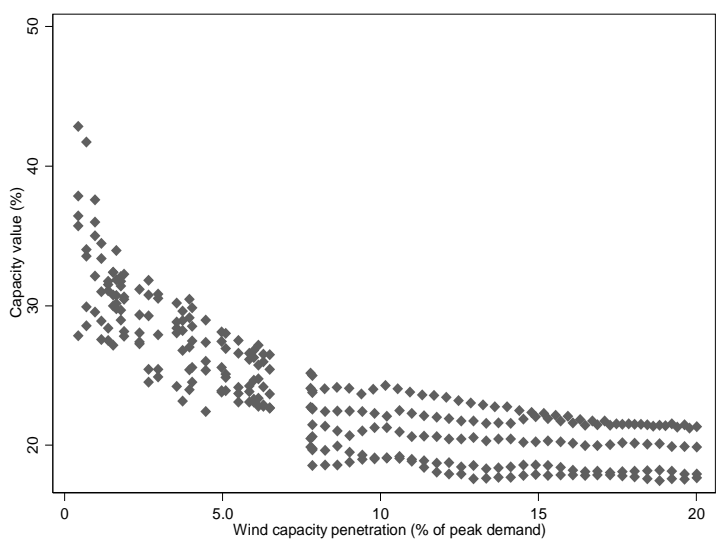

Fig 8(e): Wind capacity value in simulation 10(CI-18-3) 


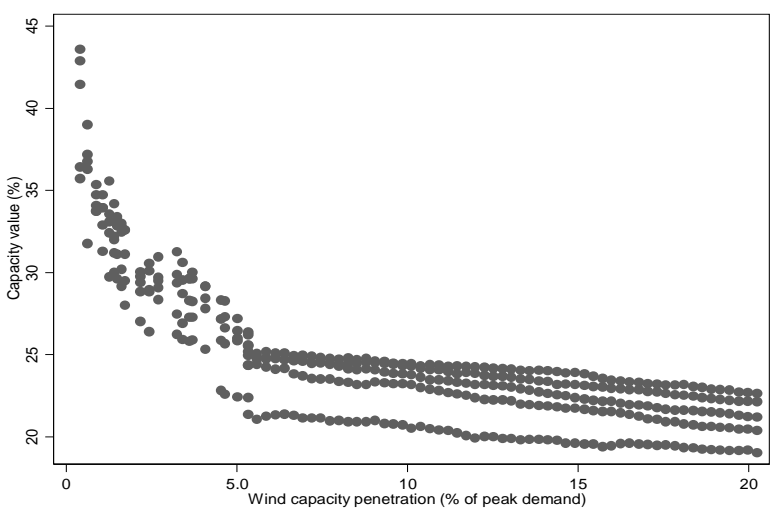

Fig 8(f): Wind capacity value in simulation 11 (CI-21-3)

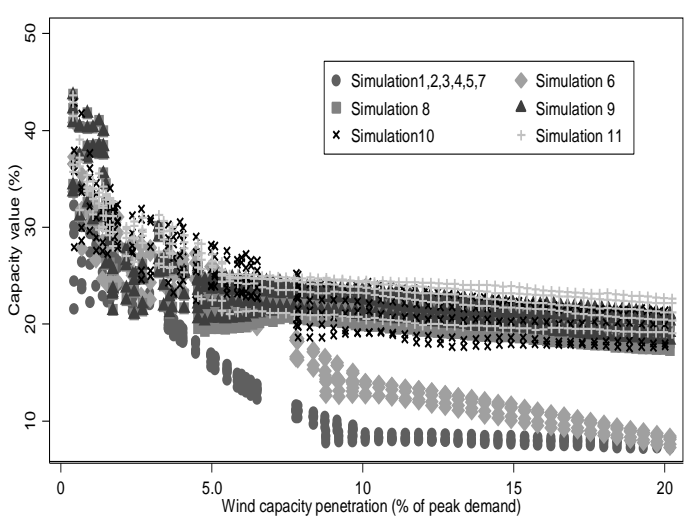

Fig 8(g): Comparative wind capacity value in eleven simulation scenarios

In order to investigate why results of capacity value in the first five and seventh simulations are identical, and what factors drive the results of capacity value in our calculation, we investigate further by assessing the effect of number of wind farms considered, the simulation approach (HS or CI), and the length of wind and load data series in the following section.

\subsection{Key Factors Driving the Capacity Value of Wind Power Calculation}

Two summaries of capacity value, one grouped by number of years and another by number of wind farms, are presented, respectively, in Fig. 9 and 10. The mean wind capacity values of eleven simulations are shown in Fig.11.

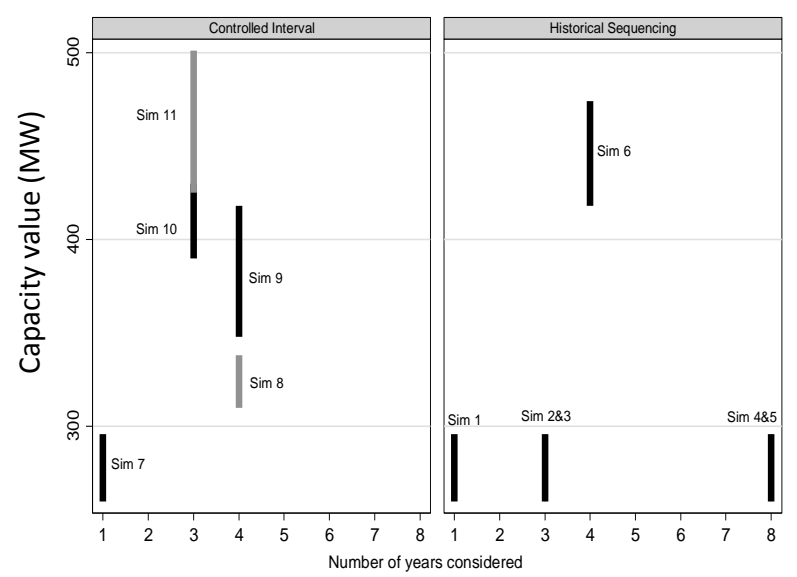

Fig.9. Effect of number of years considered on capacity value of wind power

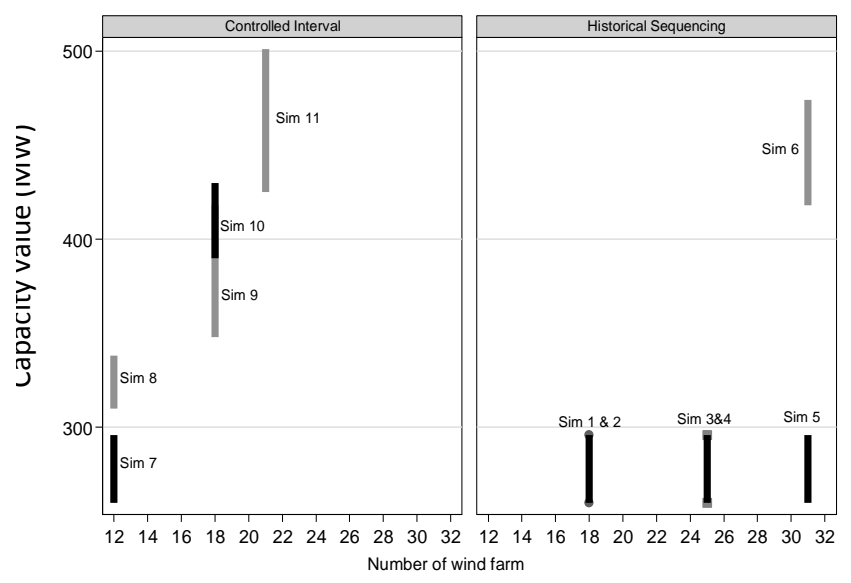

Fig.10: Effect of number of wind farms on capacity value of wind power

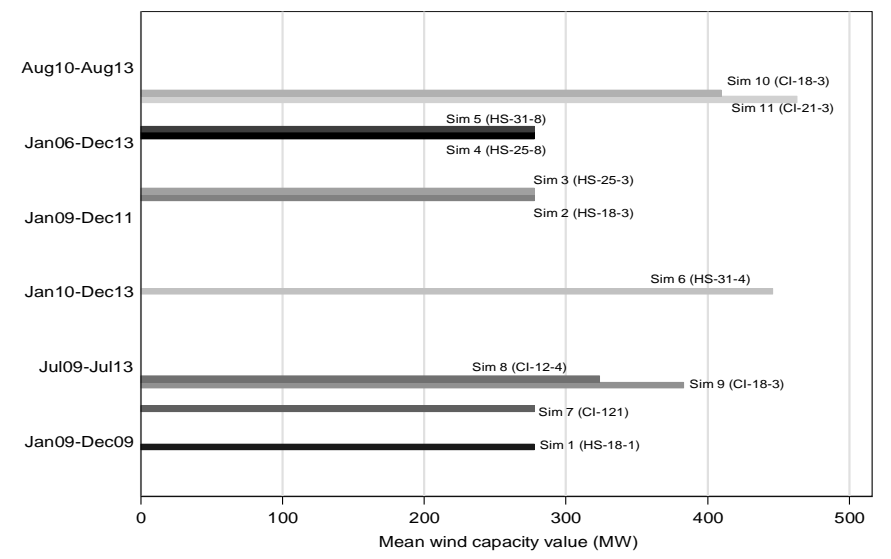

Fig.11: Summary of mean wind capacity value in eleven simulations 
Results in Fig.9 and Fig.10 reveal that number of wind farms and number of years considered in the simulations affect wind capacity values, however, they are not the dominant factor that drive our calculation results.

A remarkable point drawn from Fig.11 is that any simulation covering the period from January 2009 to June 2009 generates the same capacity value of wind power. This highlights the strong effect of extreme weather condition on the capacity value calculation. In the case of NEM wind capacity value is driven by the timing of high system risk events similar to the extreme demand event that occurred in January 2009 while wind availability was low. Higher wind generation output contribution during highrisk periods leads to higher capacity value estimates (as in the results from simulation 6, 8, 9, 10 and 11) while low wind contribution during such periods results in low capacity value estimates (results of simulation 1, 2, 3, 4, 5 and 7).

Furthermore, capacity values for wind vary by location (geography) and time. Our wind capacity value estimates are lower (accounting for $7 \%$ to $9 \%$ wind installed capacity) compared to the capacity estimates for South Australia published by AEMO [11]. AEMO used statistical analysis in its capacity value assessment and estimated that wind generation contributes at least $20 \%$ and $25 \%$ of its installed capacity for $50 \%$ of time during summer and winter, respectively. It should be noted here that South Australia has the largest installed wind capacity and wind generation in the entire NEM whereas electricity demand is lower in the State than NSW, QLD and VIC.

Finally, physical weather properties in Australia have a strong impact on electricity demand and wind generation that lead to variations in wind capacity value. Our finding is consistent with the "low wind cold snap" event in Great Britain where electricity demand is found to be extremely high over some winter days with low wind availability [25]. Other factors that could complicate capacity value estimation include the gradual development of power system and a changing climate.

\section{Conclusion}

This paper presents a comparison of capacity value of wind power using an ELCC-based method for eleven alternative simulation scenarios. Our results show that subjective factors can effect capacity value estimates. The choice of a simulation approach (historical sequencing or controlled interval), the number of wind farms and installed wind capacity, as well as the time interval for the wind and load data series all have significant impacts on capacity value results. Therefore, caution needs to be taken in interpreting and generalizing capacity value estimates because of the sensitivity of these estimates to factors determined by the researcher's approach. Particularly for power systems that are vulnerable to extreme high temperature events, capturing wind and load data points from high-risk periods in the calculation of capacity values is important for informed policy design. In the case of the Australian NEM power system, where extreme peak demand periods occurred in nine days over the last 15 years, capturing these unusual periods is critical for providing meaningful results. Capacity values are pushed down by the insignificance of wind power contribution to the super peak demand events from January 2009. The simulations incorporating such extreme events suggest that the capacity value of wind is in the range of 260 to 296 MW (7\%-9\%). For scenarios excluding the extreme events of Jan 2009, we find that the capacity estimates are higher (above $300 \mathrm{MW}$ ). The estimates for the most recent periods simulated (August 2010 to August 2013), we find the capacity value estimates are much higher (ranging between just under 400 and $500 \mathrm{MW}$ ).

The ELCC-based method we have used is a preferred method but it requires intensive wind and demand data that can be difficult to obtain but are crucial to capturing the extreme events that are critical to the robustness of the calculation. Moreover, with the gradual evolution of the power system, and the unpredictable weather conditions and evolving demand behaviours, capacity value estimates should not be taken as definite contribution values. They should be regarded as indicative figures that aid policy making and investment decisions for electrical power systems. 
The authors wish to express their gratitude to Dr Chris Dent, senior lecturer at the School of 468 Engineering and Computing Sciences from Durham University, UK, and senior member of IEEE, for 469 providing many valuable comments and discussions. They also thank AEMO for providing the high 470 resolution electricity demand and wind resource data used in the paper and the Australian Research 471 Council for support under Discovery Early Career Researcher Award (DE130100996).

\section{REFERENCES}

474 1. Billinton, R. and R.N. Allan, Reliability evaluation of power systems. Vol. 2. 1984: Plenum press

475

476

477

478

479

480

481

482

483 New York.

2. Garver, L.L., Effective load carrying capability of generating units. Power Apparatus and Systems, IEEE Transactions on, 1966(8): p. 910-919.

3. Zachary, S., C. Dent, and D. Brayshaw. Challenges in quantifying wind generation's contribution to securing peak demand. in Power and Energy Society General Meeting, 2011 IEEE. 2011. IEEE.

4. Van Wijk, A., N. Halberg, and W. Turkenburg, Capacity credit of wind power in the Netherlands. Electric Power Systems Research, 1992. 23(3): p. 189-200.

5. Voorspools, K.R. and W.D. D'haeseleer, An analytical formula for the capacity credit of wind power. Renewable Energy, 2006. 31(1): p. 45-54.

6. Martin, B. and M. Diesendorf. Calculating the capacity credit of wind power. in Proceedings 4th Biennial Conference University of Queensland, August 1980, Brisbane, Queensland, Australia. 1980.

7. Martin, B. and J. Carlin, Wind-Load Correlation and Estimates of the Capacity Credit of Wind Power: An mpirical Investigation. Wind Engineering, 1983. 7(2): p. 79.

8. Ensslin, C., et al. Current methods to calculate capacity credit of wind power, IEA collaboration. in Power and Energy Society General Meeting-Conversion and Delivery of Electrical Energy in the 21st Century, 2008 IEEE. 2008. IEEE.

9. Milligan, M. and K. Porter. Determining the capacity value of wind: An updated survey of methods and implementation. in Wind Power. 2008.

10. Haslett, J. and M. Diesendorf, The capacity credit of wind power: a theoretical analysis. Solar Energy, 1981. 26(5): p. 391-401.

11. Operator, A.E.M., South Australian wind study report. Australian Energy Market Operator (AEMO), Tech. Rep, 2013-2014.

12. Keane, A., et al., Capacity value of wind power. Power Systems, IEEE Transactions on, 2011. 26(2): p. 564-572.

13. Hasche, B., A. Keane, and M. O'Malley, Capacity value of wind power, calculation, and data requirements: the Irish power system case. Power Systems, IEEE Transactions on, 2011. 26(1): p. $420-430$.

14. Zachary, S. and C.J. Dent, Estimation of joint distribution of demand and available renewables for generation adequacy assessment. IEEE transactions on power systems., 2014.

15. Dent, C.J., et al., Application of wind generation capacity credits in the Great Britain and Irish systems, in CIGRE 2010. 2010, CIGRE: Paris.

16. Milligan, M.R. and B.K. Parsons, A comparison and case study of capacity credit algorithms for intermittent generators. 1997: National Renewable Energy Laboratory.

17. Dent, C.J. and S. Zachary, Further results on the probability theory of capacity value of additional generation, in International Conference on Probabilistic Methods Applied to Power Systems (PMAPS). 2014: Durham, England.

18. Porter, K., Determining the capacity value of wind: A survey of methods and implementation. 2005. 
19. Söder, L. and M. Amelin. A review of different methodologies used for calculation of wind power capacity credit. in 2008 IEEE POWER \& ENERGY SOCIETY GENERAL MEETING, VOLS 1-11. 2008. IEEE.

518 20. Zachary, S. and C. Dent, Estimation of Joint Distribution of Demand and Available Renewables 519 for Generation Adequacy Assessment. arXiv preprint arXiv:1412.1786, 2014.

520 21. AustralianGovernment, Securing a clean energy future: The Australian Government's climate $521 \quad$ change plan. 2011.

522 22. AEMO, Wind Integration in Electricity Grids Work Package 5: Market Simulation Studies. 2012.

523 23. AEMO, Aggregate demand and price data (1999-2014). 2014.

524 24. AEMO, Power system adequacy for the National Electricity Market. 2013.

525 25. Brayshaw, D., C. Dent, and S. Zachary, Wind generation's contribution to supporting peak electricity demand-meteorological insights. Proceedings of the Institution of Mechanical Engineers, Part O: Journal of Risk and Reliability, 2011: p. 1748006X11417503. 